\title{
Effect of CXCR5-Positive Cell Infiltration on
Immune Contexture and Patient Prognosis in Head and Neck Squamous Cell Carcinoma
}

This article was published in the following Dove Press journal: OncoTargets and Therapy

\author{
Jun Chen $\mathbb{D}^{1, *}$ \\ Xiangchao Meng ${ }^{2, *}$ \\ Qinyi Zhou' \\ Jialin Feng ${ }^{\prime}$ \\ Wenjie Zheng' \\ Zhuoying Wang' \\ jiadong Wang' \\ You Wang ${ }^{2}$
}

'Head and Neck Surgery, Ren Ji Hospital, School of Medicine, Shanghai Jiao Tong University, Shanghai, People's Republic of China; ${ }^{2}$ Bone and Joint Surgery, Ren Ji Hospital, School of Medicine, Shanghai Jiao Tong University, Shanghai, People's Republic of China

*These authors contributed equally to this work
Correspondence: Jiadong Wang

Head and Neck Surgery,Ren Ji Hospital, School of Medicine, Shanghai Jiao Tong University, Shanghai 20000I, People's Republic of China

Email wangjiadong097@163.com

You Wang

Bone and Joint Surgery,Ren Ji Hospital, School of Medicine,Shanghai Jiao Tong University,Shanghai 20000I, People's Republic of China

Email Drwangyou@I26.com
Purpose: CXCR5-positive $\left(\mathrm{CXCR} 5^{+}\right)$tumor cell infiltration has different prognostic values in different types of cancer. The objective was to evaluate the effect of $\mathrm{CXCR}^{+}$cell infiltration in head and neck squamous cell carcinoma (HNSCC).

Patients and Methods: The study included two patient cohorts: The Cancer Genome Atlas cohort (TCGA, $n=472$ ) and the Renji Hospital cohort (RJHC, $n=201$ ). The TCGA and RJHC cohorts were analyzed for CXCR5-related mRNAs and CXCR5+ cell infiltration, respectively. We then evaluated the correlation between CXCR5 mRNA and $\mathrm{CXCR}^{+}$cell infiltration in terms of overall survival and the immune contexture.

Results: The 5-year overall survival rate was significantly correlated with high CXCR5 mRNA expression and $\mathrm{CXCR}^{+}$cell infiltration in the TCGA and RJHC cohorts, respectively ( $p<0.01$ ), even after adjusting for confounders. Moreover, high CXCR5 mRNA expression was associated with more $\mathrm{CD}^{+} \mathrm{T}$ cells, $\mathrm{CD}^{+} \mathrm{T}$ cells, plasma cells, and less dendritic cells. A high CXCR5 mRNA expression was also correlated with increased expression of cytotoxic IFNG, TNFSF11 (RANKL), GZMA, GZMB, GZMK, GZMM, and PRF1 and increased expression of the immunosuppressive gene PDCD1 (PD-1), CD274 (PD-L1), CTLA4, LAG3, HAVCR2 (TIM-3), BTLA, and TIGIT.

Conclusion: HNSCC patients with a high intratumoral CXCR5 expression had a better prognosis than those with low intratumoral CXCR5 expression. Moreover, $\mathrm{CXCR}^{+}$cell infiltration could be used as an independent prognostic biomarker or as a potential therapeutic target. The presence of $\mathrm{CXCR}^{+}$cells affects the infiltration of immunocytes in head and neck cancer, differently from what was reported in other cancer types. Further randomized controlled trials or studies with more patients are needed to validate our results.

Keywords: CXCR5-producing cells, immune contexture, prognosis, head and neck squamous cell carcinoma

\section{Introduction}

The growth, proliferation, invasion, and metastasis of tumors need cross-talks between different growth factors, cytokines, and chemokines. ${ }^{1,2}$ Chemokines are chemotactic cytokines that regulate the migration of granulocytes, monocytes, and macrophages to inflammatory cells. Their functions are mediated by seven transmembrane-spanning $\mathrm{G}$ protein-coupled receptors (GPCRs), which are involved in inflammation and allergy reaction, and in tumor development and metastasis. Chemokine (CX-C motif) ligand 13 (CXCL13) and its receptor, CXCR5, represent an ideal model of the functional disruption of the chemokine ligand/receptor axis, which can cause abnormal cell 
activation and cancer promotion. ${ }^{2,3}$ Indeed, previous studies have proved that CXCR5 is associated with the development, invasion, metastasis, and prognosis of several tumors, including colorectal cancer, lung cancer, breast cancer, prostate cancer, gastric cancer, and others. ${ }^{2,9}$ However, there have been few studies focused on CXCR5 in the context of head and neck squamous cell carcinoma (HNSCC). This study aimed to investigate the value of intratumoral $\mathrm{CXCR}^{+}$cells as a prognostic marker for HNSCC patients.

\section{Methods}

\section{Study Design and Patients}

Two cohorts were analyzed in this study: The Cancer Genome Atlas cohort (TCGA, $n=472$ ) and the Shanghai Jiaotong University School of Medicine, Renji Hospital cohort (RJHC, $\mathrm{n}=201$ ). Information and clinical characteristics of patients from TCGA were retrieved from http://cbioportal.org on 31 Dec 2018. The RJHC consists of patients with HNSCC (oral cavity cancer, nasopharyngeal cancer, hypopharyngeal cancer, and laryngeal cancer) hospitalized in the Shanghai Jiaotong University School of Medicine, Renji Hospital. These patients received either surgery, radiotherapy, or chemotherapy in the period from 1 Jan 2005 to 31 Dec 2018. The institutional review board of Renji Hospital, School of Medicine, Shanghai Jiaotong University approved this study and written informed consent was collected for the RJHC cohort. The TCGA cohort was for CXCR5 mRNA expression cohort and the RJHC was for $\mathrm{CXCR}^{+}$cell infiltration cohort. The flowchart of patients enrolled and study design is shown in Figure 1.

\section{Assay Methods}

The immunohistochemistry (IHC) protocol and antibodies used are shown in Table 1. The IHC images were scanned with Image Pro Plus 6.0 (Media Cybernetics Inc., Bethesda, MD) and each section was examined under a high power field (HPF, $\times 200$ magnification). Two different pathologists evaluated the density of intratumoral cells $\left(\mathrm{CXCR}^{+}\right.$cells, $\mathrm{CD}^{+} \mathrm{T}$ cells, $\mathrm{CD}^{+} \mathrm{T}$ cells, dendritic cells, and plasma cells) reported as the mean number of positive cells/HPF from six randomized fields, three fields for each pathologist. Both were blinded from clinical data. Representative photos of immunocytes are shown in Figure 2. The tumor center area was indicated as the intratumoral region.

\section{Statistical Analysis}

Statistical analyses were performed with SPSS (version 22.0), R (version 3.4.1), and Funrich (version 3.1.3). Demographic data were analyzed by the Chi-squared test. Overall survival was analyzed by Kaplan-Meier analysis and the Log rank test. The hazard ratio of patient characteristics, independent prognosticators, and predictive factors was determined by multivariate analysis. The correlation between gene expressions was analyzed by Spearman's regression. A P-value $<0.05$ indicated statistical significance in two-tailed tests. The cutoff points for CXCR5 mRNA expression and $\mathrm{CXCR}^{+}$cells were determined by the automatic Cutoff Finder platform (http:// $\underline{\text { molpath.charite.de/cutoff). }}{ }^{4}$

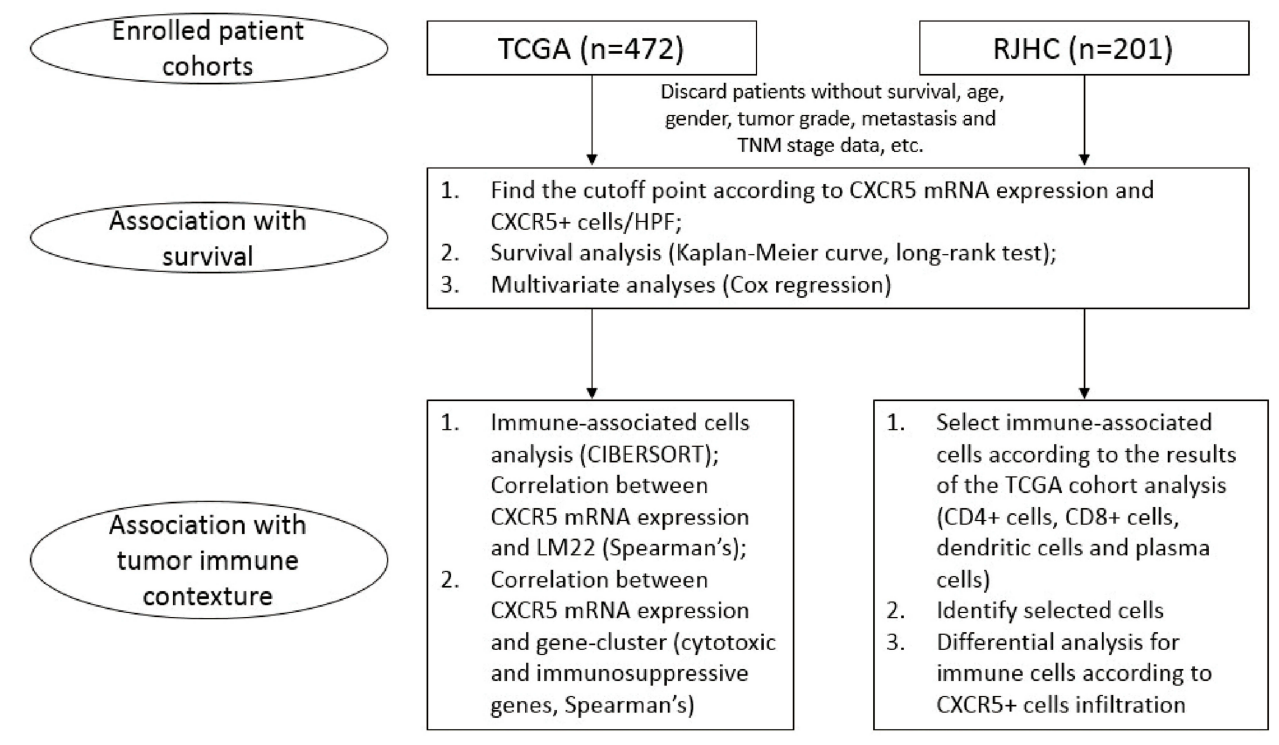

Figure I Flowchart of patients enrolled and study design. 
Table I Immunohistochemistry (IHC) Procedure and Antibodies

\begin{tabular}{|l|l|l|l|l|l|}
\hline No & Antibody Name & Description & Company & Product No. & Identical Cells \\
\hline 1 & Anti-CXCR5 Antibody & Mouse monoclonal & R\&D & MABI90, 5I,505 & CXCR5+ cells \\
2 & Anti-CD4 Antibody & Mouse monoclonal & Servicebio & GBI3064-I & CD4+ cells \\
3 & Anti-CD8 Antibody & Rabbit Polyclonal & Servicebio & GBII068-I & CD8+ cells \\
4 & Anti-CD38 Antibody & Mouse monoclonal & Servicebio & GBI4035 & Plasma cells \\
5 & Anti-CDIa Antibody & Mouse monoclonal & Servicebio & GBI4029 & Dendritic cells \\
\hline
\end{tabular}

\section{Results}

\section{Patient Cohort}

Patients' characteristics of the two cohorts are shown in Table 2. We observed heterogeneities between the cohorts: $45.9 \%$ of patients died of cancer in TCGA vs. $27.8 \%$ in RJHC, and $32.8 \%$ of the TCGA patients had a high CXCR5 mRNA expression vs. $17.1 \%$ of patients with high CXCR5 cell infiltration in RJHC. The heterogeneity could ensure the wide compatibility of our results.

\section{Prognostic Value of CXCR5 mRNA and $\mathrm{CXCR}^{+}$Cells}

The Kaplan-Meier curve of the TCGA cohort demonstrated that 5 -year overall survival rate was higher in the patients with high CXCR5 mRNA-expressing tumors than those with low CXCR5 mRNA-expressing tumors $(50.07 \%$ vs. $37.84 \%, p=0.00011)$ (Figure $3 \mathrm{~A}$ ). In a multivariate analysis that included age, gender, tumor grade, and tumor stage as confounders, the Hazard Ratio (HR) of mortality between CXCR5 mRNA highexpression vs. low-expression tumors was 0.58 (95\% CI: $0.43-0.76, \mathrm{p}<0.001$ ) (Figure 3B).
In the RJHC, the overall survival rate was longer in the group with high intratumoral $\mathrm{CXCR}^{+}$cells than that of the group with low intratumoral $\mathrm{CXCR}^{+}(\mathrm{p}=0.002)$ (Figure 4A). The 5-year overall survival rate was $81 \%$ among patients with high intratumoral $\mathrm{CXCR}^{+}$cells compared with $57 \%$ among patients with low intratumoral $\mathrm{CXCR} 5^{+}$cells. The differences remained significant even after confounders adjustment $(\mathrm{HR}=$ $0.47,95 \%$ CI: $0.26-0.84, \mathrm{p}=0.011$ ) (Figure 4B).

\section{Association of CXCR5 mRNA and $\mathrm{CXCR}^{+}$Cells with the Immune Contexture}

To confirm the changes in the immune contexture depending on the CXCR5 mRNA expression levels, we utilized the Cibersort software to calculate the relative proportion of the different immune cell types. High CXCR5 mRNA expression was associated with a higher proportion of regulatory $\mathrm{T}$ cells (Tregs, $\mathrm{P}<0.001)$, naïve $\mathrm{B}$ cells $(\mathrm{P}<0.001)$, memory resting $\mathrm{CD}^{+} \mathrm{T}$ cells $(\mathrm{P}<0.001), \mathrm{CD} 8^{+} \mathrm{T}$ cells $(\mathrm{P}<0.001)$, plasma cells $(\mathrm{P}=0.010$ ), and monocytes (Mono, $\mathrm{P}=0.041$ ), while it was correlated with a lower proportion of $\mathrm{M} 0$ macrophages $(\mathrm{P}<0.001)$, naïve $\mathrm{CD} 4+\mathrm{T}$ cells $(\mathrm{P}<0.001)$, activated mast cells
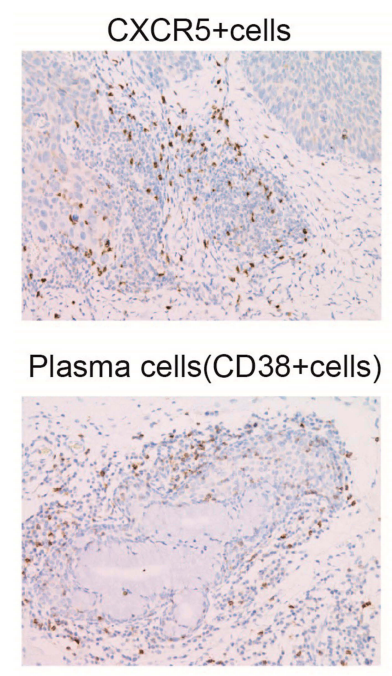
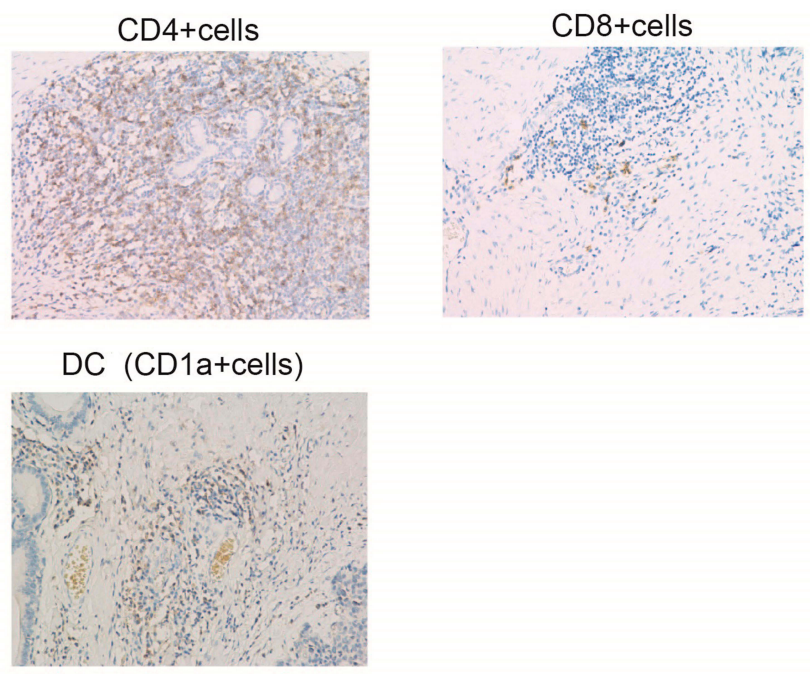

Figure 2 Representative images of immunocytes. 
Table 2 Patients' Characteristics of TCGA and RJHC

\begin{tabular}{|c|c|c|c|}
\hline & TCGA & RJHC & P value \\
\hline Age (means, std) & $61.3 \pm 12.0$ & $61.5 \pm 9.4$ & NS \\
\hline $\begin{array}{l}\text { Gender }(n, \%) \\
\text { Male } \\
\text { Female }\end{array}$ & $\begin{array}{l}342(72.5 \%) \\
130(27.5 \%)\end{array}$ & $\begin{array}{l}186(92.5 \%) \\
15(7.5 \%)\end{array}$ & $<0.01$ \\
\hline $\begin{array}{l}\text { TNM Stage }(\mathrm{n}) \\
\text { Tumor } \\
\text { T1 } \\
\text { T2 } \\
\text { T3 } \\
\text { T4 }\end{array}$ & $\begin{array}{l}35 \\
141 \\
139 \\
157\end{array}$ & $\begin{array}{l}53 \\
102 \\
32 \\
14\end{array}$ & $\begin{array}{l}\text { TI-2 Vs T3-4 } \\
\mathrm{P}<0.0 \mathrm{I}\end{array}$ \\
\hline $\begin{array}{l}\text { Node } \\
\text { N0 } \\
\text { NI } \\
\text { N2 } \\
\text { N3 }\end{array}$ & $\begin{array}{l}242 \\
85 \\
134 \\
11\end{array}$ & $\begin{array}{l}159 \\
36 \\
6 \\
0\end{array}$ & $\begin{array}{l}\text { No Vs Nx } \\
P<0.01\end{array}$ \\
\hline $\begin{array}{l}\text { Metastasis } \\
\text { MO } \\
\text { MI }\end{array}$ & $\begin{array}{l}6 \\
466\end{array}$ & $\begin{array}{l}198 \\
3\end{array}$ & $P<0.01$ \\
\hline $\begin{array}{l}\text { Alcohol History (n) } \\
\text { Yes } \\
\text { No }\end{array}$ & $\begin{array}{l}324 \\
148\end{array}$ & $\begin{array}{l}113 \\
88\end{array}$ & $P<0.01$ \\
\hline $\begin{array}{l}\text { Smoking History } \\
\text { 0-No } \\
\text { I-Mild } \\
\text { 2-Moderate } \\
\text { 3-Severe }\end{array}$ & $\begin{array}{l}112 \\
159 \\
68 \\
133\end{array}$ & $\begin{array}{l}58 \\
51 \\
50 \\
42\end{array}$ & $\begin{array}{l}\text { SO-I Vs S2-3 } \\
P<0.01\end{array}$ \\
\hline $\begin{array}{l}\text { Clinical Stage } \\
\text { Stage I } \\
\text { Stage II } \\
\text { Stage III } \\
\text { Stage IV }\end{array}$ & $\begin{array}{l}19 \\
90 \\
100 \\
263\end{array}$ & $\begin{array}{l}52 \\
103 \\
30 \\
16\end{array}$ & $P<0.01$ \\
\hline $\begin{array}{l}\text { Grade } \\
\text { GI } \\
\text { G2 } \\
\text { G3 } \\
\text { G4 }\end{array}$ & $\begin{array}{l}54 \\
290 \\
121 \\
7\end{array}$ & $\begin{array}{l}62 \\
118 \\
21 \\
0\end{array}$ & $P<0.01$ \\
\hline $\begin{array}{l}\text { Types of Tumors } \\
\text { Hypopharynx } \\
\text { Nasopharynx } \\
\text { Larynx } \\
\text { Oral }\end{array}$ & $\begin{array}{l}9 \\
0 \\
106 \\
357\end{array}$ & $\begin{array}{l}20 \\
6 \\
166 \\
9\end{array}$ & $P<0.01$ \\
\hline
\end{tabular}

$(\mathrm{P}<0.001)$, activated dendritic cells $(\mathrm{aDC}, \mathrm{P}=0.005)$, and activated $\mathrm{NK}$ cells (aNK, $\mathrm{P}=0.030$ ) (Figure $5 \mathrm{~A}$ ).

The same cell type was localized in RJHC to validate the results in the TCGA cohort (Figure 5B). We observed that a high CXCR5+ cell infiltration was correlated with higher CD4 $+\mathrm{T}$ cells (Figure 5B-1), CD8 $+\mathrm{T}$ cells (Figure 5B-2), CD38 plasma cells (Figure 5B-3), and higher CD 1a+ DC (Figure 5B-4) infiltration (All $\mathrm{P}<0.05$ ).

Moreover, the expression of factors mediating cytotoxic functions, ${ }^{5-8}$ such as IFNG, TNFSF11 (RANKL), GZMA, GZMB, GZMK, GZMM, and PRF1, was positively associated with high CXCR5 mRNA expression (Figure 6A) (Spearman's $\rho=0.30,0.22,0.34,0.34,0.44,0.51$, and 0.38 , respectively; all $\mathrm{P}<0.05$ ). In addition, the expression of some immunosuppressive factors, ${ }^{7,8}$ such as PDCD1 (PD-1), CD274 (PD-L1), CTLA4, LAG3, HAVCR2 (TIM-3), BTLA, and TIGIT, was also positively associated with a high CXCR5 mRNA expression (Figure 6B) (Spearman's $\rho=0.42,0.22,0.46,0.35,0.40$, 0.57 , and 0.52 , respectively; all $\mathrm{P}<0.05$ ).

\section{Discussion}

CXCR5, also called Type I Burkitt lymphoma receptors (BLR-1), is a chemokine receptor belonging to the CX-C motif family. CXCR5 is mainly present in mature B cells, some $\mathrm{CD} 4^{+} \mathrm{T}$ and $\mathrm{CD} 8^{+} \mathrm{T}$ cells subtypes, and skin-derived dendritic cells. Their functions are mediated by seven transmembrane-spanning $G$ protein-coupled receptors (GPCRs), which regulate the recruiting of B cells back to the lymph node follicle and promote lymph nodes development. CXCL13, a member of the CX-C motif family, is the ligand of CXCR5. CXCL13 is mostly in the stomach, liver, and lymph nodes, where it recruits B cells, regulates the maturity and development of B cells and is involved in the immune system signaling. The CXCL13/CXCR5 interaction plays an important role in the harmonization of the humoral immunity. ${ }^{2,3,9}$

In this study, we have shown that the expression of CXCR5 mRNA and the presence of intratumoral CXCR $5^{+}$ cells are prognostic markers in two different HNCC patient cohorts, TCGA and RJHC, respectively. This is in agreement with previous studies that reported that CXCR5 is correlated to poor prognosis in several tumors, such as colorectal cancer, lung cancer, breast cancer, prostate cancer, gastric cancer, and others. ${ }^{2,9}$ Our analysis showed that the 5-year overall survival rate was higher in the patients with high CXCR5 mRNA-expressing tumors than those with low CXCR5 mRNA-expressing. Moreover, we observed that the overall survival was longer among the patients with higher intratumoral $\mathrm{CXCR}^{+}$cells group than those with lower intratumoral $\mathrm{CXCR}^{+}$cells. Four previous studies showed that, in oral squamous cell carcinoma cells, CXCL13 and/or CXCR5 
A
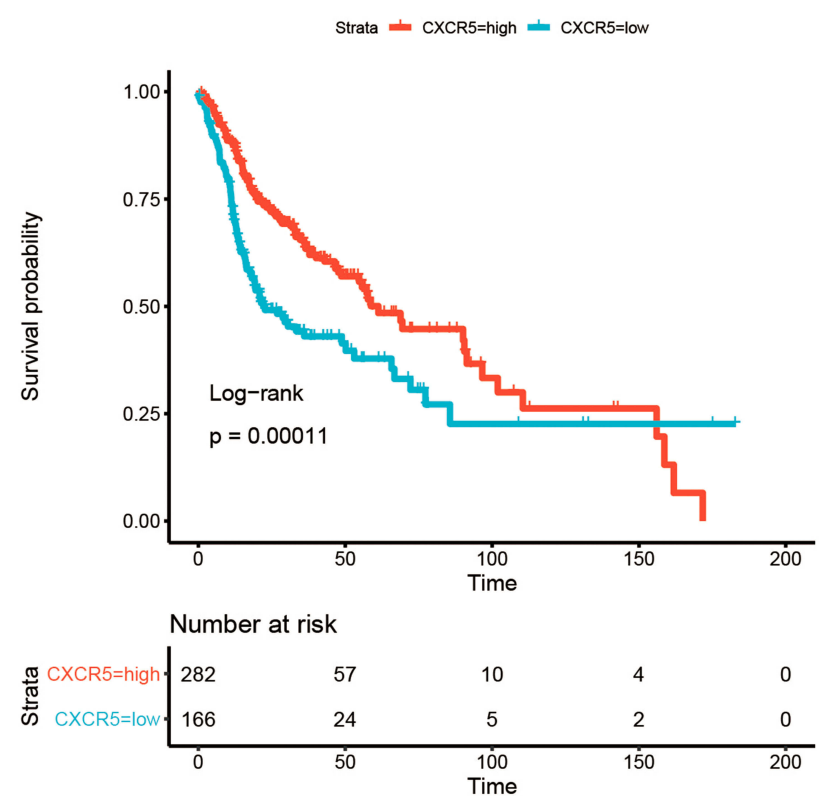

B

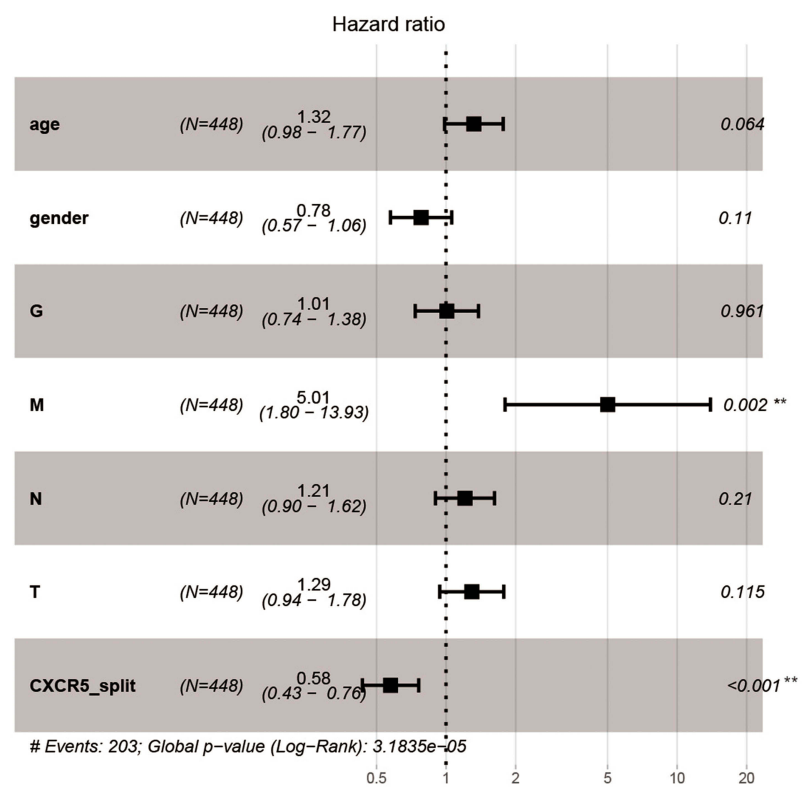

Figure 3 Relationship between CXCR5 and patient survival in the TCGA cohort. (A) Overall survival curves. (B) Multivariate Cox analysis for CXCR5 mRNA expression. $* * \mathrm{P}<0.01$.

A

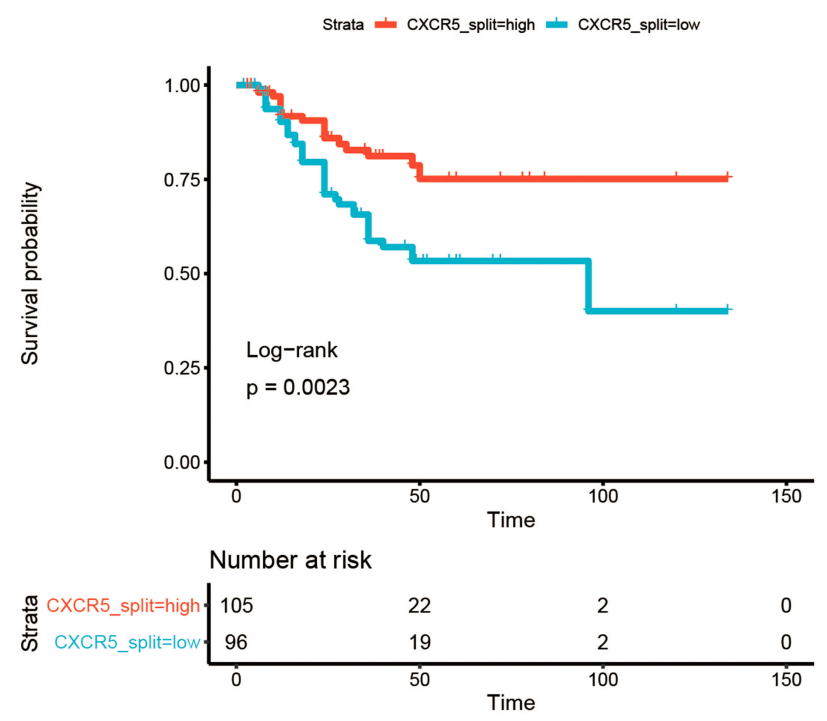

B

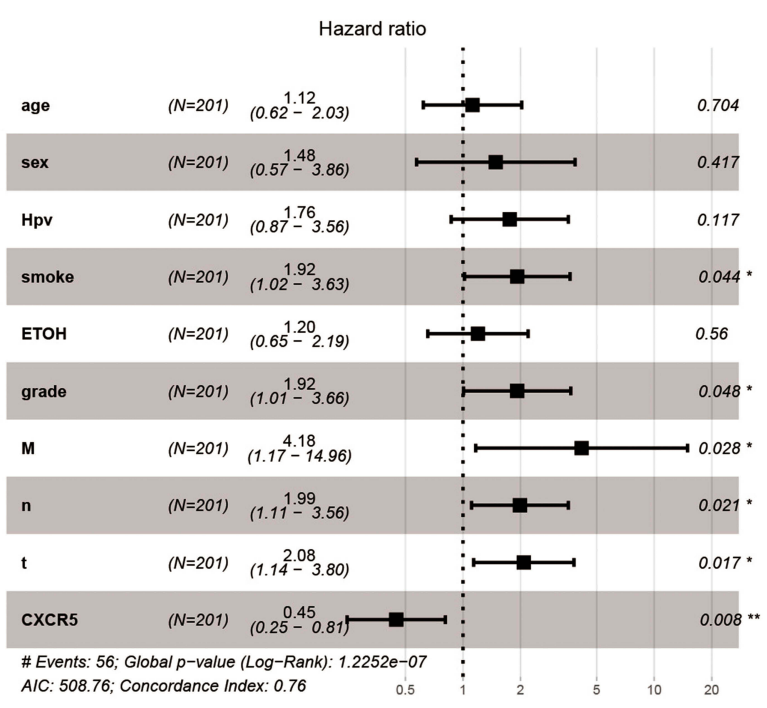

Figure 4 Relationship between CXCR5 and patient survival in the RJHC. (A) Overall survival curves. (B) Multivariate Cox analysis for CXCR5 ${ }^{+}$cell infiltration. $* \mathrm{P}<0.05$, $* * \mathrm{P}<0.01$.

are correlated with tumor development, invasion, and metastasis, in apparent contrast with our results. ${ }^{10-13}$ However, two of these studies were conducted in vitro, one was an in vivo study using a mouse model, and the other one compared cancer patients with healthy controls. To date, our study is the only clinical study showing that high CXCR5 mRNA expression or high intratumoral $\mathrm{CXCR}^{+}$cells are correlated to a better overall survival rate in HNSCC patients.

Tumor immune contexture can provide valuable information about the status of tumor immune surveillance. ${ }^{2,5,21}$ By comparing the immunocyte infiltration between groups with 

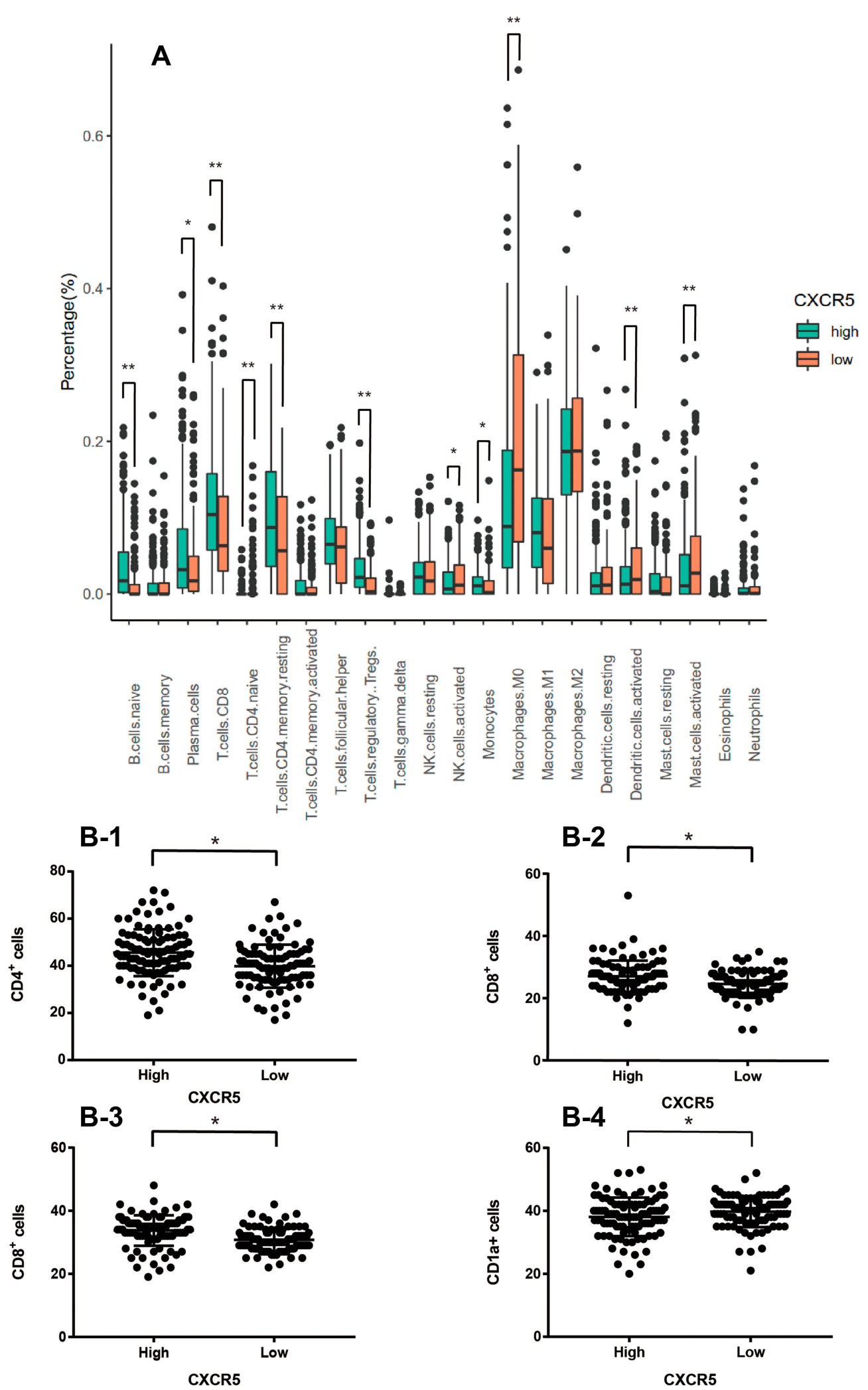

Figure 5 Comparison of infiltration levels of various immunocytes in the two cohorts. (A) Comparison of the expression levels between high and low CXCR5 mRNA expression groups in the TCGA cohort. (B) Comparison of infiltration of different immune cell types between high and low CXCR5+ cell infiltration groups in the RJHC, including CD4+ $T$ cells (B-I), CD8+ $T$ cells (B-2), CD38 plasma cells (B-3), and CD la $+\mathrm{DC}(\mathrm{B}-4)$. $* \mathrm{P}<0.05$, **P $<0.0 \mathrm{I}$. 
A

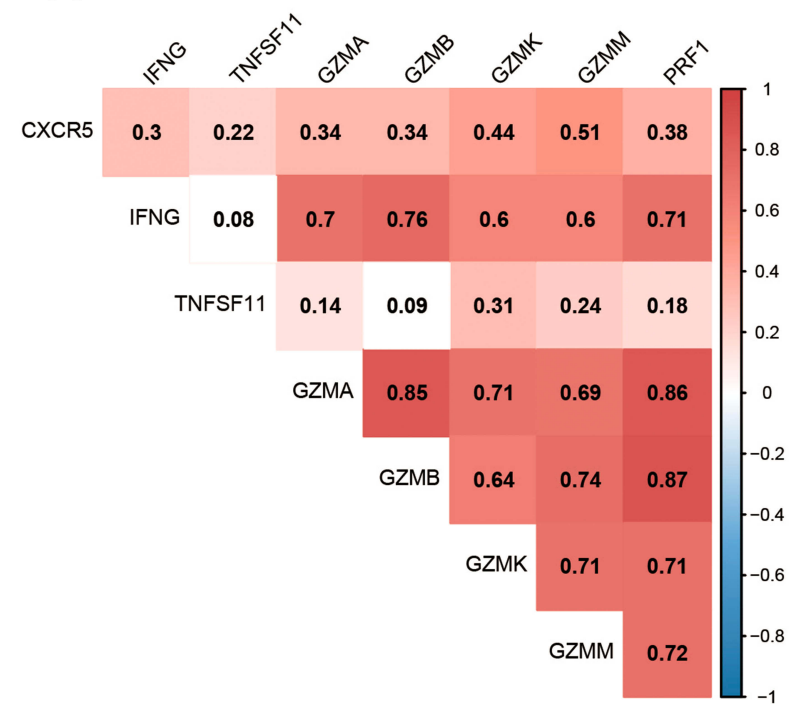

$\mathbf{B}$

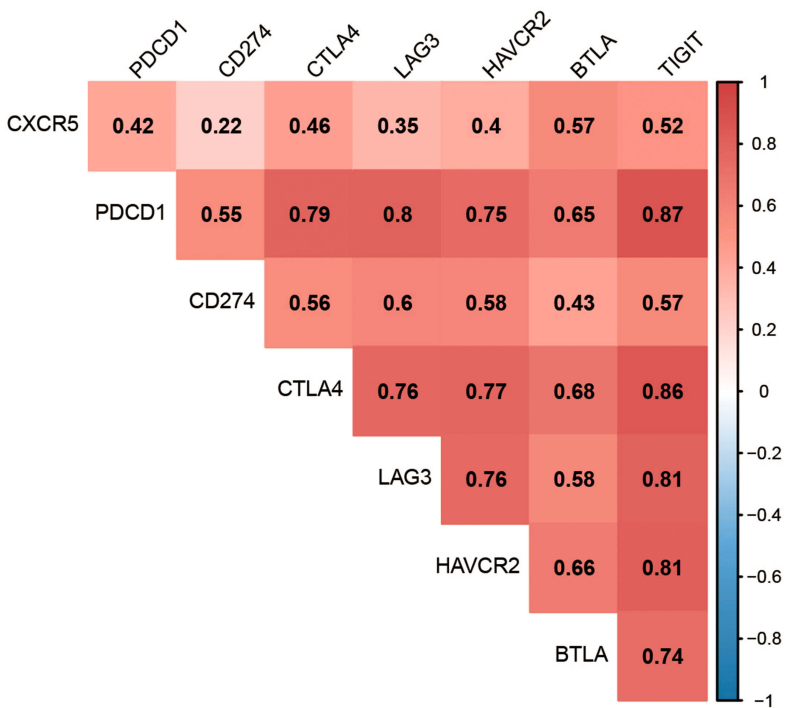

Figure 6 Association of CXCR5 mRNA expression with immune-associated gene expression. (A) Spearman correlation between CXCR5 mRNA expression and cytotoxic molecules. (B) Spearman correlation between CXCR5 mRNA expression and immunosuppressive molecules.r.

tumors expressing high and low levels of CXCR5 mRNA, we found that tumors highly expressing CXCR5 mRNA expression and having more $\mathrm{CXCR}^{+}$cell infiltration had higher levels of antitumor B cells, memory $\mathrm{CD}^{+} \mathrm{T}$ cells, $\mathrm{CD}^{+} \mathrm{T}$ cell, and plasma cells and lower levels of pro-tumor DC infiltration. $\mathrm{CD}^{+} \mathrm{T}$-cells are capable of stopping tumor development and the presence of $\mathrm{CD} 8^{+} \mathrm{T}$-cells in the tumor site is correlated with positive patient prognosis, although the existence of immunosuppressive mechanisms by the tumor limits their effectiveness; $\mathrm{CD}^{+} \mathrm{T}$-cells by themselves are rarely curative without an external therapy. ${ }^{14,15}$ Memory $\mathrm{T}$ cells are the principal cell type involved in the quick initiation of the adaptive immune response. Moreover, they confer rapid host protection upon cognate antigen-mediated activation and directly kill abnormal cells. ${ }^{15,16}$ These functions are in agreement with our results showing that the presence of memory $\mathrm{CD}^{+} \mathrm{T}$ cells positively correlates with prognosis. Plasma cells play an essential role in humoral immunity and cellular immunity. ${ }^{5,21}$ This is consistent with our data showing that a high level of plasma cells is correlated to a better prognosis. The presence of immature DCs, displaying low NF- $\mathrm{KB}$ activation and low MHC class II and co-stimulatory molecule expression, are defective antigenpresenting cells that induce T cell anergy and exhaustion. The presence of immature DC might also induce immunotolerance. Moreover, the maturation process of $\mathrm{CD} \mathrm{a}^{+}$immature DCs may be inhibited by tumor-secreted factors. ${ }^{17-19}$ This is consistent with our results showing that low levels of protumor $\mathrm{CD}^{+} \mathrm{a}^{+} \mathrm{DC}$ infiltration in tumors highly-expressing
CXCR5 mRNA and $\mathrm{CXCR}^{+}$cell infiltration are correlated to better overall survival rate. Sandel et al showed that the number of immature DCs in the tumor did not affect the disease outcome. ${ }^{18}$ However, another study showed that patients with higher levels of immature DCs (i.e. CD1a ${ }^{+}$) in the tumor had a lower disease-free survival rate, which is quite consistent with our results. ${ }^{17}$ The correlation between DCs and patient survival is still controversial: the discrepancy in different studies could be due to differences in the intratumoral localization and by the different biology of the tumor types. More clinical studies are needed to resolve this controversy. Our data suggest that $\mathrm{CXCR}^{+}$cells in head and neck cancer have a role in mediating the infiltration of different immunocytes.

Furthermore, in this study, we report a positive correlation between CXCR5 mRNA expression and the expression of cytotoxic proteins such as IFNG, TNFSF11, GZMA, GZMB, GZMK, GZMM, and PRF1. ${ }^{5-8}$ CXCR5 remained an independent prognostic marker even after adjusting for these factors as confounders. Whereas, the mechanism of action underlying the relationship between CXCR5 and immune contexture should have further basic researches and clinical studies. In addition, this study showed a positive correlation between CXCR5 mRNA expression and the expression of immunosuppressive proteins such as PDCD1, CD274, CTLA4, LAG3, HAVCR2, and BTLA. ${ }^{5,20-22}$ Thus, it is likely that patients who have high CXCR5 mRNA-expressing tumors can obtain more benefits from PDCD1, CD274, CTLA4, LAG3, HAVCR2, 
and BTLA inhibitors than other patients. Further clinical studies are needed to assess the value of CXCR5 mRNA expression and $\mathrm{CXCR}^{+}$cells in the context of therapy with targeted treatment and immune checkpoint inhibitors (ICIs) for head and neck cancers. ${ }^{23,24}$

Although we analyzed two different patient cohorts, there are some limitations to our study. First, we observed heterogeneities in the two cohorts. Second, some clinical characteristics were different between the two cohorts. Thus, our results should be validated by further multicenter, randomized control trials. Moreover, it would be interesting to investigate the role of CXCR5 in the development of metastasis.

In conclusion, in this study, we report that a high CXCR5 expression in HNSCC patients is correlated to a better prognosis than those with low CXCR5 expression. This is probably caused by the infiltration of immunocytes mediated by the presence of $\mathrm{CXCR}^{+}$cells. Based on the available experimental research and clinical studies, this is a typical feature of HNSCC, different from other types of cancer. $\mathrm{CXCR}^{+}$cells infiltration could be used as an independent biomarker for early diagnosis and treatment, or as a potential therapeutic target to improve outcomes and life quality for HNSCC patients.

\section{Funding}

This study was funded by the Medical and Industrial Cross Project of Shanghai Jiaotong University (YG2017QN45) and Renji Cultivation Fund (PY2018-IIA-02). All these study sponsors had no roles in the study design, collection, analysis, and interpretation of data.

\section{Disclosure}

The authors declare no conflicts of interest.

\section{References}

1. Lacalle RA, Blanco R, Carmona-Rodriguez L, et al. Chemokine receptor signaling and the hallmarks of cancer. Int Rev Cell Mol Biol. 2017;331:181-244.

2. Hussain M, Adah D, Tariq M, et al. CXCL13/CXCR5 signaling axis in cancer. Life Sci. 2019;227:175-186. doi:10.1016/j.lfs.2019.04.053

3. MacDonald RJ, Yen A. CXCR5 overexpression in HL-60 cells enhances chemotaxis toward CXCL13 without anticipated interaction partners or enhanced MAPK signaling. In Vitro Cell Dev Biol Anim. 2018;54(10):725-735. doi:10.1007/s11626-018-0293-z

4. Budczies J, Klauschen F, Sinn BV, et al. Cutoff finder: a comprehensive and straightforward web application enabling rapid biomarker cutoff optimization. PLoS One. 2012;7:e51862. doi:10.1371/journal.pone. 0051862

5. Wang JT, Li H, Zhang H, et al. Intratumoral IL17-producing cells infiltration correlate with antitumor immune contexture and improved response to adjuvant chemotherapy in gastric cancer. Ann Oncol. 2019;30(2):266-273. doi:10.1093/annonc/mdy505
6. Balar AV, Galsky MD, Rosenberg JE, et al. Atezolizumab as first-line treatment in cisplatin-ineligible patients with locally advanced and metastatic urothelial carcinoma: a single-arm, multicentre, Phase 2 trial. Lancet. 2017;389(10064):67-76. doi:10.1016/S0140-6736(16)32455-2

7. Ghatalia P, Gordetsky J, Kuo F, et al. Prognostic impact of immune gene expression signature and tumor infiltrating immune cells in localized clear cell renal cell carcinoma. J Immunother Cancer. 2019;7(1):139. doi:10.1186/s40425-019-0621-1

8. Gong Z, Jia Q, Chen J, et al. Impaired cytolytic activity and loss of clonal neoantigens in elderly patients with lung adenocarcinoma. $J$ Thorac Oncol. 2019;14(5):857-866. doi:10.1016/j.jtho.2019.01.024

9. Wang GZ, Cheng X, Zhou B, et al. The chemokine CXCL13 in lung cancers associated with environmental polycyclic aromatic hydrocarbons pollution. Elife. 2015;4:e09419. doi:10.7554/eLife.09419

10. Sambandam Y, Sundaram K, Liu A, et al. CXCL13 activation of c-Myc induces RANK ligand expression in stromal/preosteoblast cells in the oral squamous cell carcinoma tumor-bone microenvironment. Oncogene. 2013;32:97-105. doi:10.1038/onc.2012.24

11. Ziober AF, Patel KR, Alawi F, et al. Identification of a gene signature for rapid screening of oral squamous cell carcinoma. Clin Cancer Res. 2006;12:5960-5971. doi:10.1158/1078-0432.CCR-06-0535

12. Yuvaraj S, Griffin AC, Sundaram K, et al. A novel function of CXCL13 to stimulate RANK ligand expression in oral squamous cell carcinoma cells. Mol Cancer Res. 2009;7:1399-1407. doi:10.1158/1541-7786.MCR-08-0589

13. Pandruvada SN, Yuvaraj S, Liu X, et al. Role of CXC chemokine ligand 13 in oral squamous cell carcinoma associated osteolysis in athymic mice. Int $J$ Cancer. 2010;126:2319-2329. doi:10.1002/ ijc. 24920

14. Peske JD, Woods AB, Engelhard VH. Control of CD8 T-cell infiltration into tumors by vasculature and microenvironment. Adv Cancer Res. 2015;128:263-307.

15. Pizzolla A, Wakim LM. Tissue resident CD8 memory $\mathrm{T}$ cell responses in cancer and autoimmunity. Front Immunol. 2018;9:2810. doi:10.3389/fimmu.2018.02810

16. Lauvau G, Soudja SM. Mechanisms of memory T cell activation and effective immunity. Adv Exp Med Biol. 2015;850:73-80.

17. Gulubova MV, Ananiev JR, Vlaykova TI, et al. Role of dendritic cells in progression and clinical outcome of colon cancer. Int $J$ Colorectal Dis. 2012;27(2):159-169. doi:10.1007/s00384-011-1334-1

18. Sandel MH, Dadabayev AR, Menon AG, et al. Prognostic value of tumor-infiltrating dendritic cells in colorectal cancer: role of maturation status and intratumoral localization. Clin Cancer Res. 2005;7:2576-2582. doi:10.1158/1078-0432.CCR-04-1448

19. Annalisa Legitimo A, Consolini R, Failli A, et al. Dendritic cell defects in the colorectal cancer. Hum Vaccin Immunother. 2014;10 (11):3224-3235. doi:10.4161/hv.29857

20. Motz GT, Coukos G. Deciphering and reversing tumor immune suppression. Immunity. 2013;39(1):61-73. doi:10.1016/j.immu ni.2013.07.005

21. Chan AW-H, Zhang Z, Chong CC-N, et al. Genomic landscape of lymphoepithelioma-like hepatocellular carcinoma. $J$ Pathol. 2019;249(2):166-172. doi:10.1002/path.5313

22. Shimizu K, Iyoda $T$, Okada $M$, et al. Immune suppression and reversal of the suppressive tumor microenvironment. Int Immunol. 2018;30(10):445-454. doi:10.1093/intimm/dxy042

23. Hegde PS, Karanikas V, Evers S. The where, the when, and the how of immune monitoring for cancer immunotherapies in the era of check- point inhibition. Clin Cancer Res. 2016;22(8):1865-1874. doi:10.1158/1078-0432.CCR-15-1507

24. Tumeh PC, Harview CL, Yearley JH, et al. PD-1 blockade induces responses by inhibiting adaptive immune resistance. Nature. 2014;515(7528):568-571. doi:10.1038/nature13954 


\section{Publish your work in this journal}

OncoTargets and Therapy is an international, peer-reviewed, open access journal focusing on the pathological basis of all cancers, potential targets for therapy and treatment protocols employed to improve the management of cancer patients. The journal also focuses on the impact of management programs and new therapeutic

Submit your manuscript here: https://www.dovepress.com/oncotargets-and-therapy-journal agents and protocols on patient perspectives such as quality of life, adherence and satisfaction. The manuscript management system is completely online and includes a very quick and fair peer-review system, which is all easy to use. Visit http://www.dovepress.com/ testimonials.php to read real quotes from published authors. 